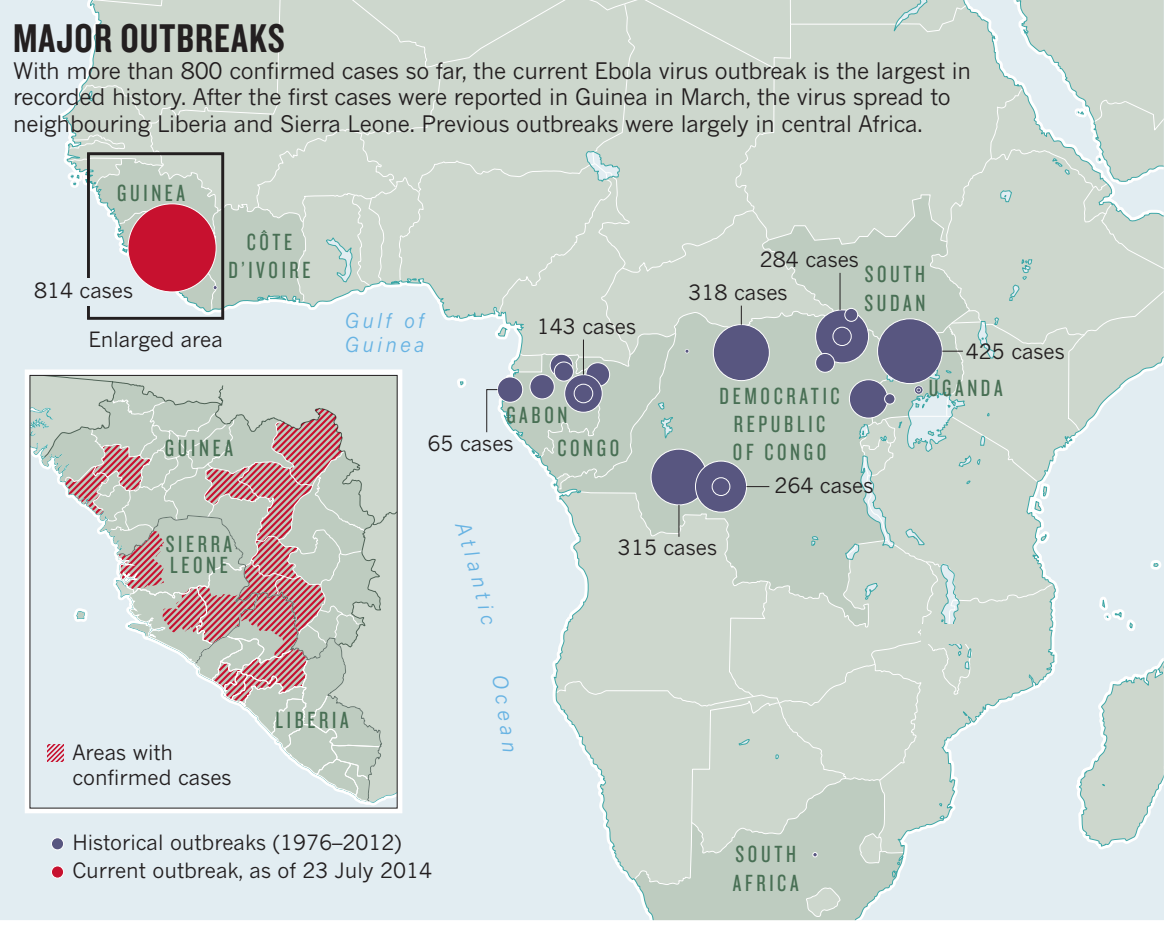

INFECTIOUS DISEASES

\title{
Ebola treatments caught in limbo
}

\section{Logistics and lack of funds keep experimental drugs and vaccines from being used in Africa outbreak.}

\section{BY SARA REARDON}

$\mathrm{M}$ edical relief workers fighting a burgeoning Ebola outbreak in West Africa have not been welcomed with open arms. Death was all that the hazmat-suited visitors seemed to bring. Most patients who entered the makeshift hospitals died, their families forbidden to handle their bodies. Rumours flew that these newcomers were harvesting organs and conducting fatal experiments.

So people scattered, making a bad situation worse. The outbreak, the biggest recorded in Ebola history, has so far killed more than 670 people in West Africa and is thought to have infected about 400 more, and it shows no sign of abating (see 'Major outbreaks').

Doctors have no cure to offer the infected. Understaffed clinics must make do with isolating infected people, finding and quarantining their families, and educating the public on how to avoid spreading the disease. Although several vaccines and treatments for Ebola do exist, they are stalled in various stages of testing owing to a lack of funding and of international demand. Even if they did move forwards, it would be years rather than months before the measures would reach the people in need.

For researchers such as Heinz Feldmann, a virologist at the US National Institute of Allergy and Infectious Disease (NIAID) in Hamilton, Montana, the situation seems like it could have been avoided. In 2005, he published a vaccine platform based on vesicular stomatitis virus (VSV) that has since yielded an Ebola vaccine that is effective in macaques (T. W. Geisbert et al. PLoS Med. 2, e183; 2005). But money is not available to take the next step - testing the vaccine's safety in healthy humans, says Feldmann. Compared with malaria or HIV, "Ebola is just not that much of a public-health problem worldwide", he says, and consequently draws little interest from public or private funders.

"What works for Ebola is good old-fashioned public health," says Thomas Frieden, director of the US Centers for Disease Control and Prevention in Atlanta, Georgia. "It would be great to have a vaccine, but it's not easy to do and not clear who you'd test it on."

The VSV vaccine seems to be a promising option because it can be used either preventively or just after a person is infected. In 2009, it was used on a German lab technician who had accidentally pricked herself with a needle carrying Ebola virus. Although it is unclear whether she was ever infected, the technician survived and suffered no ill effects from the vaccine. "Everybody in my lab would volunteer to take the vaccine," says Thomas Geisbert, a microbiologist at University of Texas Medical Branch in Galveston who is also working on the medicine.

The NIAID Vaccine Research Center in Bethesda, Maryland, has developed a vaccine that is carried by a chimpanzee adenovirus, similar to the virus that causes the common cold. The institute hopes to begin testing in healthy people as early as September. Barney Graham, deputy director of the research centre, says that the institute is talking with the Food and Drug Administration (FDA) to speed up the approval process, a position that is strengthened by the outbreak in West Africa.

Biotechnology companies are also developing treatments at a pace that could be accelerated. Mapp Biopharmaceutical in San Diego, California, is testing combinations of monoclonal antibodies that target the virus, and also hopes to begin human trials soon. And with US\$140 million from the US Department of Defense, Tekmira in Burnaby, Canada, is testing a treatment called TKM-Ebola, which uses small RNA molecules to bind the virus and target it for destruction. The company began testing the vaccine in humans in January, but on 3 July, the FDA put the study on hold until the company could provide more data on how the treatment works. Tekmira says that it is confident it will be able to restart the trial soon.

The timing of the outbreak is "unfortunate", says Armand Sprecher, a public-health specialist at Médecins Sans Frontières (also known as Doctors Without Borders) in Brussels. "If this had happened a year or two from now maybe we'd be in a better position."

A treatment could be approved by the FDA on a 'compassionate use' basis, but that process would have to mesh with a host country's rules. "A country has to request these things; it's not something we can force on them," says Gene Olinger, a virologist at the contract research organization MRIGlobal in Frederick, Maryland. "We have to follow their internal policies for drug development and for testing." -

\section{CORRECTION}

In the News Feature 'Hello, Governor' (Nature $511,402-404 ; 2014)$, the number of co-authors for the consensus statement was given as 13 instead of 14 . And the title of the report omitted the word 'scientific'. Finally, it was Governor Brown, not Elizabeth Hadly, who delivered the report to political leaders. 